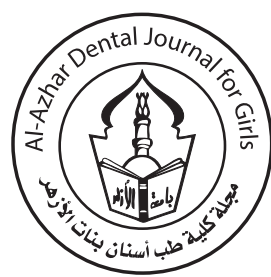

\title{
Evaluation of Remineralization Potential of Two Agents and pH Cycling on Early Enamel Lesions
}

\author{
Nehal G. Abosamra ${ }^{1 *}$, Heba E. Eltayeb ${ }^{2}$, Fatma Alzhraa M. Abdul-Rahman ${ }^{3}$
}

Codex : 01/22.01

azhardentj@azhar.edu.eg

http://adjg.journals.ekb.eg

DOI: $10.21608 /$ adjg.2021.39074.1287

Restorative Dentistry

(Removable Prosthodontics, Fixed

Prosthodontics, Endodontics, Dental Biomaterials, Operative Dentistry)

\section{KEYWORDS}

CPP-ACP, nano-hydroxyapatite, remineralization.

\begin{abstract}
Purpose: The purpose of this study was to evaluate \& compare the remineralization potential of two remineralizing agents on artificially induced enamel carious lesions via $\mathrm{pH}$ cycling. This assessment has been conducted via Surface microhardness analysis and energy dispersive X-ray(EDX) analysis. Materials and Methods: In this in vitro study, 20 human teeth were sectioned mesio-distally to obtain 40 enamel samples where artificial carious lesions were induced using an acidic buffer solution. Then samples were randomly divided into two groups $(n=20)$ according to the material used. The first group was for Casein phosphopeptide-amorphous calcium phosphate(CPP-ACP) \&the second was for Nano-hydroxyapatite paste(nHAP). Each group was further subdivided into two subgroups $(\mathrm{n}=10)$ according to whether subjected to $\mathrm{pH}$ cycling or not. The surface microhardness was measured for enamel by Vickers hardness tester at baseline, demineralization and after the application of remineralizing agents in a 15days pH-cycling model and without it. Similarly, the mineral content of the samples was estimated by EDX analysis. The data were analyzed using independent t-test, ANOVA test and Tukey's post-hoc test. Results: Results of the microhardness showed that without $\mathrm{pH}$ cycling; $\mathrm{CPP}-\mathrm{ACP}$ recorded a higher statistically significant difference than nHAP. Additionally, after $\mathrm{pH}$ cycling, CPP-ACP recorded a non-significant difference than nHAP. Moreover, EDX results revealed that the $\mathrm{Ca} / \mathrm{P}$ ratio for the $\mathrm{nHAP}$ group recorded the highest statistically significant difference than all tested groups followed by CPP-ACP without $\mathrm{pH}$ cycling, baseline and CPP-ACP after $\mathrm{pH}$ cycling, respectively. Conclusion: $\mathrm{CPP}-\mathrm{ACP}$ and $\mathrm{nHAP}$ both had a positive effect on causing remineralization of enamel. Nano-hydroxyapatite was more effective as compared to $\mathrm{CPP}-\mathrm{ACP}$, in increasing the calcium and phosphorus content of enamel in both presence and absence of $\mathrm{pH}$ cycling.
\end{abstract}

* Paper extracted from Thesis titled "Evaluation of Remineralization Potential of Two Agents and pH Cycling on Early Enamel Lesions"

1. General practitioner in Ministry of health, Alexandria, Egypt.

2. Assistant professor and Head of Dental Biomaterials Department, Faculty of Dental Medicine for Girls, Al-Azhar University, Cairo, Egypt.

3. Lecturer of Dental Biomaterials Department, Faculty of Dental Medicine for Girls, Al-Azhar University, Cairo, Egypt.

*Corresponding author email: nehalgama191@gmail.com 


\section{INTRODUCTION}

Dental caries is described as a cyclic process, the metabolism of a fermentable substrate by plaque flora results in periods of demineralization, followed by periods of remineralization ${ }^{(1)}$. The ratio between cyclic demineralization and remineralization process is the key that determines the progression or prevention of tooth caries ${ }^{20}$. Demineralization process of enamel is the dissolution and finally loss of carbonated hydroxyapatite minerals from tooth structure due to $\mathrm{pH}$ decline of the oral environment (3). High consumption of acidic beverages as well as acids produced by food fermentation by oral cariogenic bacteria leads to an oral environment with a lower level of mineral ion content in comparing to the enamel mineral and demineralization phase initiated $^{(3,4)}$.

Furthermore, the existence of the demineralization phase for a long period may lead to excessive mineral loss and finally enamel cavitation ${ }^{(3-5)}$. Fortunately, dental caries is a slow process ${ }^{(6)}$ allowing the early stage of enamel demineralization to be reversible ${ }^{(3,7)}$, when oral $\mathrm{pH}$ rise, mineral deposition back to the enamel takes place in the process of remineralization $^{(3,4,5)}$.

Remineralizing agents are part of a new era of dentistry aimed at controlling the demineralization/ remineralization cycle, depending upon the microenvironment around the tooth. The rationale of these agents is the remineralization of early carious and non-carious white lesions, advocating a biological or therapeutic approach rather than the traditional surgical approach. With a clearer understanding of these remineralizing agents and new technologies accessible to dentists, we can provide quality dental care using minimally invasive methods ${ }^{(8)}$. Non-invasive treatment protocol of demineralized enamel lesions as a more conservative procedure by different remineralizing agents would bring a major approach in the clinical management of these enamel defects ${ }^{(9)}$.
Numerous types of remineralizing agents and remineralizing techniques have been researched and many of them are being used clinically, with significantly predictable positive results. The recent researches on remineralization are based on biomimetic remineralization materials, having the capability to create apatite crystals within the completely demineralized collagen fibers ${ }^{(10)}$. Therefore, focus of dental research has shifted to the development of methodologies for the early detection and use of noninvasive techniques by using remineralizing agents for the effective management of carious lesions ${ }^{(11)}$.

Casein phosphopeptides have recently been used extensively in the field of preventive dentistry. They are utilized alone or as (casein phosphopeptides with amorphous calcium phosphate) CPP-ACP or (casein phosphopeptides with amorphous calcium fluoride phosphate) CPP-ACFP. CPP-ACP has proved to promote the remineralization of the enamel subsurface carious lesions and decrease the demineralization ${ }^{(12)}$. One of the major properties of CPP is to improve the bioavailability of calcium and phosphate ions level via supersaturation with these ions to enhance remineralization ${ }^{(13)}$. The CPP-ACP also acts as a reservoir of bioavailable calcium and phosphate and maintains the solution supersaturated, thus facilitating remineralization ${ }^{(14)}$.

Hydroxyapatite is a calcium phosphate compound with the molecular formula $\mathrm{Ca}_{10}\left(\mathrm{PO}_{4}\right) \mathrm{OH}_{2}$ and a calcium-to phosphorus ratio of $1: 67^{(15)}$. Nano-hydroxyapatite (n-HAP) is one of the most biocompatible and bioactive materials and has gained immense popularity in dentistry nowadays ${ }^{(10)}$. Recently, numerous in vitro attempts have been made to prepare enamel-like materials using biomimetic systems that contain nano-apatites or different organic materials used as analogues to organic matrix mainly in the form of slurries, solutions or pastes ${ }^{(16)}$. Due to the similarity between Nano- HAP (n-HAP) and the apatite crystal of tooth enamel in terms of morphology and crystal structure, it can substi- 
tute for the natural mineral constituent of enamel for repair biomimetically ${ }^{(10)}$. During the nano-HA remineralization, the circular crystals of nano-HA get sedimented onto the tooth enamel and directly fill up defects and micropores on demineralized surfaces. As a result, there is decrease in defects and cavities of the enamel surface and the increase in hardness of the enamel surface ${ }^{(8)}$. Also, the nanoscale ranges from 1 to $100 \mathrm{~nm}$. From these dimensions derives a distinct activity of the particles. Their large reaction surface and small size enhance the hydration of the material, thus gaining better physical and chemical characteristics ${ }^{(17)}$. Moreover, nanohydroxyapatite is hydrophilic and has a greater surface area than conventional hydroxyapatite crystals, so they have better wettability and form a thin layer on enamel surface that bonds to tooth structure $^{(18)}$.

Furthermore, remineralization of the teeth is directly related to changes in the mineral content, microhardness, and surface morphology. Therefore, in this study, Vickers microhardness and energydispersive X-ray spectroscopy (EDX) were used to evaluate the remineralizing potential of CPP-ACP and nHAP pastes on early enamel carious lesions in permanent teeth $^{(19)}$.

\section{MATERIAL AND METHODS}

A total of 20 freshly extracted human teeth were used in this study. Ethical approval for the use of extracted human teeth was obtained in accordance with guidelines from research ethics committee approval Faculty of Dental Medicine -Al-Azhar University for girls. Teeth with cracks, fractures, carious lesions of the crown or the root, restorations, and previous endodontic treatment were excluded. The teeth were stored at $4^{\circ} \mathrm{C}$ in thymol solution until used. They were used not more than 1-month postextraction ${ }^{(20)}$. The teeth were thoroughly washed, scrubbed, and scaled to remove surface debris and contaminants.

\section{Enamel samples' preparation:}

In this study, the teeth were sectioned horizontally at the level of the cement-enamel junction, separating the crown and root parts of the tooth. The root portion was discarded ${ }^{(20)}$. Separation was done by a diamond-coated band saw under continuous water spray. Each tooth was sectioned mesiodistally into two halves $(n=40)$. Each half was trimmed to produce cubic shaped blocks thereafter. Each enamel block was $(4 \mathrm{~mm} \times 4 \mathrm{~mm})^{(21)}$.

Polymethyl-methacrylate (PMMA) blocks were constructed on which the samples were individually mounted on them. The superficial surface of enamel was flattened with water-cooled carborundum discs (1200 grit; Water Proof Silicon Carbide Paper, Struers, Germany). Subsequently, any remnants of abrasive paper on the enamel blocks were cleaned with methanol. Then, a diamond paste $(15 \mu \mathrm{m}$ diamond paste, Struers) was used to polish the surfaces, removing about $100 \mu \mathrm{m}$ of the superficial enamel layer resulting in a flat surface. Thereafter, these slabs were cleaned with distilled water and methanol ${ }^{(21)}$.

\section{Samples' grouping:}

The samples were divided randomly into two groups ( $n=20)$ according to the type of remineralizing material applied; the first group was for CPP-ACP and the second was for nHAP.

Each of the two groups was further subdivided into two subgroups $(n=10)$ according to whether subjected to $\mathrm{pH}$ cycling or not.

\section{Preparation of nano-hydroxyapatite:}

Hydroxyapatite nanorods were synthesized by a wet chemical reaction method and preparation of nano grade calcium Phosphate $\left(\mathrm{Ca}_{2} \mathrm{PO}_{4}\right)$. Preparation was done by Nano-Gate company. Nasr city (Cairo, Egypt).

\section{Solution preparation:}

\section{Demineralization solution:}

The demineralization solution was composed of calcium chloride $(\mathrm{CaCl} 2.2 \mathrm{H} 2 \mathrm{O}) 2.2 \mathrm{mmol} / \mathrm{l}$, 
potassium dihydrogen phosphate $(\mathrm{KH} 2 \mathrm{PO} 4.7 \mathrm{H} 2 \mathrm{O})$ $2.2 \mathrm{mmol} / \mathrm{l}$, and lactic acid $0.05 \mathrm{mmol} / \mathrm{l}$. The final $\mathrm{pH}$ was adjusted to 4.5 with $50 \%$ sodium hydroxide $(\mathrm{NaOH})$. It was used thereafter during the test in $\mathrm{pH}$ cycling ${ }^{(22)}$.

\section{Remineralization solution:}

The remineralization solution was composed of calcium chloride $(\mathrm{CaCl} 2) 1.5 \mathrm{mmol} / \mathrm{l}$, potassium chloride $(\mathrm{KCl}) 50 \mathrm{mmol} / \mathrm{l}$, potassium dihydrogen phosphate (KH2PO4) $0.9 \mathrm{mmol} / \mathrm{l}$, and Tris buffer $20 \mathrm{mmol} / \mathrm{l}^{(22)}$.

\section{Treatment solution:}

The pastes of the remineralization materials (CPPACP and nHAP) and the remineralizing solution were diluted together in the ratio $1(9 \mathrm{~g}): 3(27 \mathrm{~mL})$ to prepare the treatment solution. The mixture was rendered homogenous by using a magnetic stirrer at $350 \mathrm{rpm}$ for $1 \mathrm{~min}$. From this mixture $4.0 \mathrm{~mL}$ was recommended for each tooth. Just before treatment, fresh slurry should be prepared for each group. The treatment solutions of nHAP were ultrasonicated immediately after preparation ${ }^{(23)}$.

\section{Preparation of early artificial caries lesions:}

All enamel specimens were immersed in $8 \mathrm{~mL}$ of demineralization solution for $72 \mathrm{~h}$ to induce artificial caries formation and then rinsed 3-consecutive times by $20 \mathrm{~mL}$ distilled water for 20 seconds ${ }^{(21)}$.

\section{pH-cycling model:}

After demineralization of all the tested samples, half of the samples $(\mathrm{n}=10)$ were subjected to $\mathrm{pH}$ cycling model and the other half $(n=10)$ were treated directly without $\mathrm{pH}$ cycling. The samples subjected to $\mathrm{pH}$ cycling were first immersed in treatment solution for $3 \mathrm{~min}$ followed by remineralizing solution for $1 \mathrm{hr}$ then reimmersed in treatment solution for 3 $\min$. The samples were then exposed to remineralizing solution for $2 \mathrm{hrs}$ then to demineralizing solution for $2 \mathrm{hrs}$ followed by remineralizing solution for 2 more hours. After that, the samples were immersed in treatment solution for 3 min followed by remineralization for $1 \mathrm{hr}$ then reimmersed in treatment solution for $3 \mathrm{~min}$. Lastly, the samples were left in the remineralizing solution over night for $16 \mathrm{hrs}$. After each treatment, the specimens were washed under running distilled water. The treatment regime was repeated daily for 15 days. ${ }^{(21)}$.

\section{Samples' testing:}

For both microhardness and EDX analysis, all samples were first tested at baseline and then after demineralization. After that, all the samples were retested after treatment with remineralizing agents with $\mathrm{pH}$ cycling and with no $\mathrm{pH}$ cycling.

\section{Microhardness testing:}

Microhardness values of all samples were measured using digital Vickers microhardness tester and Vickers Microhardness Software (Wilson ${ }^{\circledR}$ Instruments 402 MVD Microhardness Tester). A load of $100 \mathrm{~g}$ was applied to the surface for $15 \mathrm{sec}$. Three indentations were placed on the surface, and the average value of the three readings was recorded. Distances between the indentations were set as minimum $120 \mu \mathrm{m}$. Vickers microhardness number (VHN) was then computed automatically by the software program and displayed on the screen of the microhardness tester ${ }^{(22)}$.

\section{Quantitative analysis by EDX:}

The samples were evaluated quantitatively using the EDX. The energy-dispersive X-ray spectroscopy (EDX) (Jeol JSM- IT200 InTouchScope ${ }^{\text {TM }}$ was used to measure the lesion quantitatively; it is a method of microanalysis integrated into a scanning electron microscope. An electron is expelled from an inner shell of an atom, and when an outer shell electron takes the place of the missing electron, energy is released in the form of "X-ray radiation". The X-rays are then analyzed to provide details on the surface's elemental distribution "Calcium and phosphorous" ions concentrations. Then, they were converted into $\mathrm{Ca} / \mathrm{P}$ ratio for each tested group ${ }^{(24)}$. 


\section{Statistical analysis:}

All data were statistically analyzed by computer using statistical program SPSS ver. 18.0 (Statistical Package for Scientific Studies, SPSS, Inc., Chicago, IL, USA) for Windows. Numerical data was presented as mean and standard deviation values. The mean and the standard deviation were estimated for quantitative data. The data analysis was performed using Paired t-test, independent t-test, ANOVA test and Tukey's post-hoc test.

\section{RESULTS}

\section{Microhardness of enamel:}

The results of Vickers microhardness (VHN) of the enamel at baseline, after demineralization and after treatment with and without $\mathrm{pH}$ cycling were illustrated in table (1).

Results showed that the highest mean value was recorded at baseline (334.02 \pm 49.65$)$ and the lowest value was recorded after demineralization (232.8 \pm 50.69$)$. Moreover, all tested groups recorded statistically significant lower mean values than the baseline except for CPP-ACP group with no $\mathrm{pH}$ cycling which showed a non-significant difference with baseline as revealed by Tukey's post hoc test.

\section{Effect of $\mathrm{pH}$ cycling:}

Within each treatment groupCPP-ACPand nHAP, the $\mathrm{pH}$ cycling had no statistically significant effect on the microhardness mean values. Additionally, comparing the two treatment groups, results showed that after $\mathrm{pH}$ cycling, non-significant difference was recorded between CPP-ACP (274.62 \pm 42.93$)$ and nHAP (263.03 \pm 54.81$)$. Furthermore, without pH cycling; CPP-ACP (290.30 \pm 24.53$)$ recorded a higher statistically significant difference than nHAP (242.25 \pm 21.79$)$.

\section{EDX:}

The mineral content of the samples estimated by EDX analysis was represented in table (2). The mass \% of both $\mathrm{Ca}$ and $\mathrm{P}$ ions were recorded by EDX at baseline, after demineralization and after treatment and without $\mathrm{pH}$ cycling, then the $\mathrm{Ca} / \mathrm{P}$ ratio was obtained for each group.

The results revealed that $\mathrm{Ca}$ and $\mathrm{P}$ mass\% after demineralization recorded statistically lowest significant difference compared to all other tested groups. The nHAP group recorded the highest statistically significant difference in both $\mathrm{Ca}$ mass $\%$ and $\mathrm{P}$ mass $\%$ compared to all other tested groups.

Moreover, the $\mathrm{Ca} / \mathrm{P}$ ratio for the $\mathrm{nHAP}$ group recorded the highest statistically significant difference compared to all tested groups with $\mathrm{Ca} / \mathrm{P}$ ratio $(2.23 \pm 0.2),(2.10 \pm 0.11)$ after $\mathrm{pH}$ cycling and without $\mathrm{pH}$ cycling, respectively. Followed by CPP-ACP without $\mathrm{pH}$ cycling (1.95 \pm 0.08$)$, baseline $(1.90 \pm 0.08)$ and CPP-ACP after $\mathrm{pH}$ cycling $(1.89 \pm 0.06)$, whereas, the least $\mathrm{Ca} / \mathrm{P}$ ratio was recorded after demineralization (1.76 \pm 0.09$)$.

\section{Effect of pH cycling:}

Within each treatment group, $\mathrm{pH}$ cycling had a statistically non-significant effect on the mineral content $(\mathrm{Ca}$ and $\mathrm{P}$ mass \%) of the enamel and on the $\mathrm{Ca} / \mathrm{P}$ ratio.

Table (1): Comparison of enamel microhardness (VHN) according to treatment.

\begin{tabular}{|c|c|c|c|c|c|c|c|}
\hline & \multirow[b]{2}{*}{ Baseline } & \multirow{2}{*}{$\begin{array}{c}\text { After } \\
\text { demineralization }\end{array}$} & \multicolumn{2}{|c|}{ CPP-ACP } & \multicolumn{2}{|c|}{ n-HAP } & \multirow{2}{*}{ P-value } \\
\hline & & & $\begin{array}{l}\text { After pH } \\
\text { cycling }\end{array}$ & $\begin{array}{l}\text { Without pH } \\
\text { cycling }\end{array}$ & After $\mathbf{p H}$ cycling & $\begin{array}{l}\text { Without pH } \\
\text { cycling }\end{array}$ & \\
\hline Mean \pm SD & $334.02^{\mathrm{a}} \pm 49.65$ & $232.81^{\mathrm{c}} \pm 50.69$ & $274.62^{\mathrm{b}} \pm 42.93$ & $290.30^{\mathrm{a}, \mathrm{b}} \pm 24.53$ & $263.03^{\mathrm{b}, \mathrm{c}} \pm 54.81$ & $242.25^{\mathrm{c}} \pm 21.79$ & $0.00 *$ \\
\hline P-value & \multicolumn{2}{|c|}{$0.00 *$} & \multicolumn{2}{|c|}{$0.3292 \mathrm{~ns}$} & \multicolumn{2}{|c|}{$0.2799 \mathrm{~ns}$} & \\
\hline
\end{tabular}

Significance level $p \leq 0.05$, * significant, $n s=$ non-significant 
Table (2): EDX calcium and phosphorus analysis of enamel according to treatment.

\begin{tabular}{|c|c|c|c|c|c|c|c|c|}
\hline \multirow[b]{2}{*}{ Element } & & \multirow[b]{2}{*}{ Base-line } & \multirow{2}{*}{$\begin{array}{c}\text { After } \\
\text { demine- } \\
\text { ralization }\end{array}$} & \multicolumn{2}{|c|}{ СРP-ACP } & \multicolumn{2}{|c|}{ nHAP } & \multirow{2}{*}{ P-value } \\
\hline & & & & $\begin{array}{l}\text { After pH } \\
\text { cycling }\end{array}$ & $\begin{array}{l}\text { Without } \\
\text { pH cycling }\end{array}$ & $\begin{array}{l}\text { After pH } \\
\text { cycling }\end{array}$ & $\begin{array}{l}\text { Without } \\
\text { pH cycling }\end{array}$ & \\
\hline \multirow{3}{*}{$\begin{array}{l}\text { Calcium } \\
\text { mass \% }\end{array}$} & Mean & $29.55^{\mathrm{b}}$ & $26.23^{c}$ & $31.14^{\mathrm{b}}$ & $31.53^{\mathrm{b}}$ & $39.9^{\mathrm{a}}$ & $36.40^{\mathrm{a}}$ & \multirow{2}{*}{$0.00 *$} \\
\hline & SD & 1.52 & 2.29 & 1.43 & 1.09 & 3.5 & 2.14 & \\
\hline & $\begin{array}{l}\mathrm{P} \text { (pairwise } \\
\text { comparison) }\end{array}$ & \multicolumn{2}{|c|}{$0.0013 *$} & \multicolumn{2}{|c|}{$0.64 \mathrm{~ns}$} & \multicolumn{2}{|c|}{$0.09 \mathrm{~ns}$} & \\
\hline \multirow{3}{*}{$\begin{array}{c}\text { Phosphorus } \\
\text { mass } \%\end{array}$} & Mean & $15.57^{\mathrm{c}}$ & \multirow{2}{*}{$\begin{array}{c}14.87^{\mathrm{d}} \\
0.68\end{array}$} & $16.48^{\mathrm{b}}$ & $16.22^{\mathrm{b}}$ & $17.9^{\mathrm{a}}$ & $17.35^{\mathrm{a}}$ & \multirow{2}{*}{$0.00 *$} \\
\hline & SD & 0.56 & & 0.37 & 0.92 & 0.4 & 0.45 & \\
\hline & $\begin{array}{l}\mathrm{P} \text { (pairwise } \\
\text { comparison) }\end{array}$ & \multicolumn{2}{|c|}{$0.022 *$} & \multicolumn{2}{|c|}{$0.574 \mathrm{~ns}$} & \multicolumn{2}{|c|}{$0.074 \mathrm{~ns}$} & \\
\hline \multirow{3}{*}{$\mathrm{Ca} / \mathrm{P}$ ratio } & Mean & $1.90^{\mathrm{b}}$ & $1.76^{\mathrm{c}}$ & $1.89^{\mathrm{b}}$ & $1.95^{\mathrm{b}}$ & $2.23^{\mathrm{a}}$ & $2.10^{\mathrm{a}}$ & \multirow{2}{*}{$0.00 *$} \\
\hline & SD & 0.08 & 0.09 & 0.06 & 0.08 & 0.20 & 0.11 & \\
\hline & $\begin{array}{l}\mathrm{P} \text { (pairwise } \\
\text { comparison) }\end{array}$ & \multicolumn{2}{|c|}{$0.0017 *$} & \multicolumn{2}{|c|}{$0.217 \mathrm{~ns}$} & \multicolumn{2}{|c|}{$0.239 \mathrm{~ns}$} & \\
\hline
\end{tabular}

Significance level $p \leq 0.05, *$ significant Tukey's post hoc test: Within the same comparison, means sharing the same superscript letter are not significantly different.

\section{DISCUSSION}

In the recent era of minimal intervention dentistry, various agents have been produced to enhance remineralization potential of the demineralized enamel (25). Therefore, the aim of this study was to evaluate the remineralization ability of Casein phosphopeptide agent versus nano-hydroxyapatite agent. The effect of $\mathrm{pH}$ cycling was also investigated.

There is a high-level of evidence supporting the remineralizing efficacy of casein phosphopeptideamorphous calcium phosphate (CPP-ACP) from studies around the world. Evidence is now emerging that CPP-ACP may also have a beneficial influence on the dental plaque, microbial ecology and homeostasis. The ecological cariostatic effects of CPP-ACP are believed to be mediated predominantly through its anti-adhesion, buffering and biofilm disrupting actions ${ }^{(26)}$.

In this study, HAP nanorods was used as one of the most biocompatible and bioactive materials ${ }^{(27)}$. As, the coating effect of the micro-structured hydroxyapatite nanoparticles reintegrates the enamel with a biomimetic film reproducing the structure and the morphology of the biologic hydroxyapatite of the enamel. It was demonstrated that the coating is due to the deposit of a new layer of apatite, which presents fewer particles than the natural enamel, not based on the chemicalphysical changes occurring in fluorinated toothpastes. Moreover, it shows resistance to brushing as a consequence of chemical bonds between the synthetic and natural crystals of the enamel ${ }^{280}$. The remineralization process of early carious lesions has been proved to be influenced by the morphological structure and the surface chemical properties of nHAP. The concentration as well as the precipitation rate and amount of nHAP are in direct relation. As the concentration increases the other properties would also increase leading to the deposition of considerable amounts of $\mathrm{Ca}^{+2}$ and $\mathrm{PO}^{-4}$, hence extensively improving remineralization ${ }^{(29)}$.

In the present research, Vickers hardness method was used to check microhardness because it was non-destructive, very reliable, rapid, and economical as compared to other hardness tests ${ }^{(30)}$. More- 
over, EDX was used as it is a microanalytical technique that undergoes elemental analysis at the ultrastructural level ${ }^{(31)}$.

In the current study, both nHAP and CPP-ACP pastes were able to remineralize early enamel lesions. The results displayed that the microhardness of demineralized enamel surfaces in all groups significantly decreased, implying loss of minerals. This could be attributed to the fact that all the samples were subjected to the same demineralizing solution and immersion time for the aim of standardization.

Comparing the results of the two treatment groups without $\mathrm{pH}$ cycling, CPP-ACP showed significantly higher mean microhardness value than nHAP. Additionally, CPP-ACP with no $\mathrm{pH}$ cycling recorded a non-significant difference than baseline. This could be clarified by the ability of Casien phosphopeptide to form nano clusters with amorphous calcium phosphate ensuring a reservoir of calcium and phosphate ions which can preserve the supersaturation of saliva. Meanwhile, CPP-ACP has a buffering effect by stabilizing these ions in the solution ${ }^{(32)}$.

The $\mathrm{pH}$-cycling model presented a good mimic of the oral environmental conditions of dental caries in comparison to individual demineralization and remineralization studies ${ }^{(33)}$. For this reason, this study assessed the $\mathrm{pH}$ cycling effect on the remineralization potential of CPP-ACP and nHAP pastes on initial enamel caries lesions. When comparing the materials under different $\mathrm{pH}$ cycling conditions, results demonstrated that there was a statistically insignificant change of microhardness within the same treatment group. This was inconsistent with other studies ${ }^{(34,35)}$ which explained that the surface microhardness increased significantly when $\mathrm{pH}$ value dropped below 7.0 and the highest microhardness value was recorded at $\mathrm{pH} 4.0$, when compared with neutral group. It was stated that an acidic solution had a significant potential to improve the mineral ions deposition during mineralization when compared to a neutral solution. Those findings could be related to differences in $\mathrm{pH}$ cycling regimes, micro- hardness assessment methods, different ingredients of the pastes, and differences in the tooth structures in these studies.

On another level, EDX analysis results indicated that there was a decrease in the mass $\%$ of both calcium and phosphorus with the least $\mathrm{Ca} / \mathrm{P}$ ratio following the demineralization of samples due to loss of minerals from the enamel after exposure to the demineralizing solution. Moreover, after the treatment for 15 days, nHAP after $\mathrm{pH}$ cycling recorded the highest $\mathrm{Ca} / \mathrm{P}$ ratio in addition to increased mineral content (calcium and phosphorus) as compared to CPP-ACP group. This could be a reflection of more mineral's precipitation in the deep parts coinciding with $\mathrm{pH}$ reduction which might be directly associated with the increased solubility of nHAP in the acidic condition that was also supported by another study ${ }^{(36)}$. Furthermore, nHAP with no $\mathrm{pH}$ cycling recorded a significantly higher $\mathrm{Ca} / \mathrm{P}$ ratio than $\mathrm{CPP}-\mathrm{ACP}$ group. This might be accounted for the calcium nano-phosphate crystals that have penetrated and deposited deeper into the defects of the carious enamel, forming a "reservoir-like" precipitate of $\mathrm{Ca}^{+2}$ and $\mathrm{P}^{-4}$ ions. This precipitate ensures availability of these ions coinciding with the cariogenic process, preserving a supersaturation with enamel minerals ${ }^{(37)}$. These results were in accordance with another study ${ }^{(25)}$.

Furthermore, results showed that CPP-ACP recorded higher microhardness mean value as compared to nHAP. On the other side, it recorded lower $\mathrm{Ca} / \mathrm{P}$ ratio than $\mathrm{nHAP}$. This contradicting result might be explained by the presence of high calcium content which rapidly precipitate ions on the superficial layer of the enamel caries ${ }^{(38)}$, thus increasing the surface hardness. While it prevented the remineralization process from occurring in the depth of the lesion that would inherently prevent rapid precipitation of calcium and phosphate and therefore led to lower $\mathrm{Ca} / \mathrm{P}$ ratio. This finding was in agreement with a study which concluded that although CPP-ACP can remineralize surface lesion, it is not effective in remineralizing the early enamel caries at the subsurface level ${ }^{(39)}$. 


\section{CONCLUSIONS}

Within the limitations of the present in vitro study, the following could be concluded:

1. Both agents nHAP and CPP-ACP were effective in causing remineralization of demineralized enamel.

2. CPP-ACP showed improved hardness of enamel over nHAP with no $\mathrm{pH}$ cycling.

3. nHAP was observed to be more effective in increasing the calcium and phosphorus content of enamel compared with CPP-ACP.

\section{CONFLICT OF INTEREST}

None declared.

\section{FUNDING}

No funding was received for this study.

\section{REFERENCES}

1. Daokar SG, Kagne KS, Pawar KS, Wahane KD, Thorat TV, Mahakale CR et al. The Comparative Evaluation Of The Effects Of Antioxidants Pretreatment On Remineralization Of Demineralized Dentin - In Vitro Study. J. Interdiscip. Dent.2020;10: 67-73.

2. Chandru TP, Yahiya MB, Peedikayil FC, Dhanesh N, Srikant N, Kottayi S. Comparative evaluation of three different toothpastes on remineralization potential of initial enamel lesions: A scanning electron microscopic study. Indian J Dent Res. 2020; 31:217-23.

3. Ajaj MT, Al-Khateeb SN, Al-Batayneh OB. Effect of Different Acid Etchants on The Remineralization Process of White-Spot Lesions: An In Vitro Study. Am J Dent. 2020; 33:43-7.

4. Behrouzi P, Heshmat H, Hoorizad Ganjkar M, Tabatabaei SF, Kharazifard MJ. Effect of Two Methods Of Remineralization And Resin Infiltration On Surface Hardness Of Artificially Induced Enamel Lesions. J Dent (Shiraz). 2020; 21:12-7.

5. Ma L, Chen J, Han H, Liu P, Wang H, Lin S, et al. Effects of Lemon Essential Oil and Limonene on The Progress Of Early Caries: An In Vitro Study. Arch Oral Biol. 2020; 111:104638.
6. Hedge S, Roma M, Shetty D. Non-Fluoridated Remineralizing Agents in Dentistry. J Pharm Sci Res. 2016; 8:884-7.

7. Farooq I, Bugshan A. The Role of Salivary Contents and Modern Technologies In The Remineralization Of Dental Enamel: A Narrative Review. Version 2. F1000Res. 2020; 9:171.

8. Pande Pratik, RanaVivek, Srivastava Nikhil, Kaushik Noopur. A compendium on remineralizing agents in dentistry. 2020; 6: 247-50.

9. Abdelrahim Ramy, Basha Ibrahim, Elkadi Hamed. NonInvasive Treatment Of Demineralized Enamel By Eggshell Powder, Bioactive Glass, And Casein:Comparative Study. Egypt Dent J.2020; 66: 1741-8.

10. Arifa MK, Ephraim R, Rajamani T. Recent Advances in Dental Hard Tissue Remineralization: A Review of Literature. Int J Clin Pediatr Dent. 2019; 12:139-44.

11. Manchery N, John J, Nagappan N, Subbiah GK, Premnath P. Remineralization Potential Of Dentifrice Containing Nanohydroxyapatite On Artificial Carious Lesions Of Enamel: A Comparative In Vitro Study Dent Res J. 2019; 16: $310-17$.

12. Aimutis WR. Bioactive properties of milk proteins with particular focus on anticariogenesis. J Nutr. 2004; 134: 989-95.

13. Cross KJ, Huq NL, Reynolds EC . Casein phosphopeptides in oral health chemistry and clinical applications. Curr Pharm Des.2007;13:793-800.

14. Geeta RD, Vallabhaneni S, Fatima K. Comparative evaluation of remineralization potential of nanohydroxyapatite crystals, bioactive glass, casein phosphopeptide-amorphous calcium phosphate, and fluoride on initial enamel lesion (scanning electron microscope analysis) - An in vitro study. J Conserv Dent. 2020; 23:275-9.

15. Crisan L, Crisan B, Soritau O, Baciut M, Biris AR, Baciut G, Lucaciu O. In vitro study of biocompatibility of a graphene composite with gold nanoparticles and hydroxyapatite on human osteoblasts. J Appl Toxicol. 2015; 35:1200-10.

16. Han M, Li QL, Cao Y, Fang H, Xia R, Zhang ZH. In vivo remineralization of dentin using an agarose hydrogel biomimetic mineralization system. Sci Rep. 2017; 7:41955.

17. Ramesh SC. Dental applications of nanotechnology. Switzerland: Springer Nature.2018 .

18. Timmaiah C, Shetty P, Shetty SB, Natrajan S, Thomas AT. Comparative analysis of the remineralization potential of CPP-ACP with Fluoride, Tricalcium Phosphate and 
Nanohydroxyapatite using SEM/EDX-An In vitro study. J Clin Exp Dent 2019; 11:1120-6.

19. Konagala RK, Mandava J, Anwarullah A, Uppalapati LV, Karumuri S, Angadala PL. Synergistic Effect of Arginine on Remineralization Potential of Fluoride Varnish and Nanohydroxyapatite on Artificial Caries Lesions: An In Vitro Study. J Contemp Dent Pract. 2020; 21:1048-53.

20. Cao CY, Mei ML, Li QL, Lo EC, Chu CH. Methods for Biomimetic Remineralization of Human Dentine: A Systematic Review. Inter J Mol Sci. 2015;16: 4615-27.

21. Huang SB, Gao SS. Yu HY. Effect of Nano-Hydroxyapatite Concentration On Remineralization Of Initial Enamel Lesion In Vitro. Biomed Mater. 2009; 4: 034104.

22. Joshi C, GohilU,Parekh V,Joshi S.Comparative Evaluation of the Remineralizing Potential of Commercially Available Agents on Artificially Demineralized Human Enamel: An In vitro Study. Contemp Clin Dent. 2019; 10:605-13.

23. Amaechi BT. Protocols To Study Dental Caries In Vitro: Ph Cycling Models: Methods And Protocols, In Methods Mol Biol. (Clifton, N.J), University Of Texas Health Science Center At San Antoni.2019;1922:379-92.

24. El habashy, L., heikal, M. Effectiveness of Casein Phospopeptide Amormphous Calcium Phosphate with or without Fluoride on Reminelization Of Enamel CariesLike Lesions In Primary Teeth. Egyptian Dental Journal, 2020; 66: 799-808.

25. Sharma A, Rao A, Shenoy R, Suprahba BS..Comparative Evaluation Of Nano-Hydroxyapatite And Casein Phosphopeptide-Amorphous Calcium Phosphate On Remineralization Potential Of Early Enamel Lesions: An In Vitro Study. J Orofac Sci.2017; 9:28-33.

26. Philip N, Walsh L. The Potential Ecological Effects Of Casein Phosphopeptide-Amorphous Calcium Phosphate In Dental Caries Prevention. Aust Dent J. 2019; 64:66-71

27. Hannig M, Hannig C. Nanotechnology and its role in caries therapy. Adv Dent Res 2012; 24:53-7.

28. 28.Bossù M., Saccucci M, Salucci A, Giorgio G D, Bruni E, Uccelletti D, et al. Enamel Remineralization And Repair Results Of Biomimetic Hydroxyapatite Toothpaste On Deciduous Teeth: An Effective Option To Fluoride Toothpaste. J Nanobiotechnol. 2019; 17: 17.
29. Kim M, Kwon H, Choi Choongo HO and Kim Baek II. Combined Effects Of Nano-Hydroxyapatite And Naf On Remineralization Of Early Caries Lesion. Key Eng Mater 2007; 1347:1347-50.

30. Anshul, Kishor Jha K. Remineralization potential of GC Tooth Mousse and GC Tooth Mousse plus on initial caries like lesion of primary Teeth - An in-vitro comparative evaluation. Univ J Dent Sciences .2020; 6:3-10.

31. Sreekumar P, Kumaran P, Xavier Arun Mamachan, Varma Balagopal., Kumar S. J.Qualitative And Quantitative Comparison Of The Remineralisation Potential Of Three Suitable Materials-An In Vitro SMH And SEM Study. J Clindiag Res.2019;13: 1-4.

32. Wilson Nairn. Minimally invasive dentistry-The management of dental caries.1sted. London;2007;69-70.

33. Premnath P, JohnJ, Manchery N, Subbiah G K, Nagappan N, Subramani P. Effectiveness of Theobromine On Enamel Remineralization: A Comparative In-Vitro Study. Cureus. 2019 ;11: E5686.

34. Tschoppe P, Zandim DL, Martus P, Kielbassa AM. Enamel and Dentine Remineralization By Nano-Hydroxyapatite Toothpastes. J Dent.2011; 430-7.

35. Abdelaziz R, Mohamed A, Talaat D. Effect of two remineralizing agents on microhardness of initial enamel caries like lesions in young permanent teeth. Alexandria Dental Journal, 2019; 44: 45-9.

36. Wang Z, Jiang T, Sauro S, Wang Y, Thompson I, Watson $\mathrm{TF}$, et al. Dentine Remineralization Induced By Two Bioactive Glasses Developed For Air Abrasion Purposes. J dent.2011; 39:746-56.

37. Huang S, Gao S, Cheng L, Yu H. Remineralization Potential Of Nano-Hydroxyapatite On Initial Enamel Lesions: An In Vitro Study. Caries Res. 2011; 45: 460-8.

38. Comar LP, Souza BM, Gracindo LF, Buzalaf MA, Magalhaes AC. Impact of experimental nano-HAP pastes on bovine enamel and dentin submitted to a $\mathrm{pH}$ cycling model. Braz Dent J 2013; 24:273-8.

39. Lata S, Varghese NO, Varughese JM. Remineralization potential of fluoride and amorphous calcium phosphatecasein phosphopeptide on enamel lesions: An in vitro comparative evaluation. J Conserv Dent 2010; 13: 42-6. 